\title{
Preface to the Proceedings of the 3rd International Workshop on Intelligent Environments and Buildings (IEB'21)
}

\author{
Mohammed BAKKALI ${ }^{\mathrm{a}, \mathrm{b}, 1}$ \\ a The Bartlett School, University College London, UK \\ $\mathrm{b}$ The International University of Rabat, Morocco
}

The $3^{\text {rd }}$ International Workshop on Intelligent Environments and Buildings (IEB'21) will be held within the 17th International Conference on Intelligent Environments (IE'21) in Dubai (UAE) on $21^{\text {st }}-22^{\text {nd }}$ June 2021. Smart infrastructure is a key element for developing and managing smart cities, buildings, materials, industrial processes and so on. Smart approaches help to seal economical competitiveness and environmental sustainability. Intelligent environments require cross disciplinary approaches that encompass a multitude of disciplines including architecture, design, engineering, urban planning and other different aspects standing from decision making to local economical fabric. Continuous processes and complete cycles are required from core sciences to innovation, products' business plans and their management. Integrated design for cities, buildings and technologies with multifaceted and tailored solutions and options related to the specifications of territories. Issues such as enhancing building energy efficiency, aiming for lower $\mathrm{CO} 2$ emissions, higher air quality, higher indoor and outdoor life quality and comfort, health, efficient emergency management are very relevant challenges nowadays. In this year's edition, we will cover topics such as smart mobility, smart city, smart campus, lighting technologies, new computational approaches for urban design, net zero energy buildings, co-integration of oil and commodity places and building and urban energy modelling. The event will provide an overview of current research, developments and ongoing work on smart cities, building science and technology, and will offer a platform for discussions about future expectations. During the event, renowned researchers and innovators on smart approaches will give oral presentations and discuss their new achievements.

1 Corresponding Author: The Bartlett, UCL Institute for Environmental Design and Engineering, Central House, 14 Upper Woburn Place, WC1H 0NN London, UK; E-mail: mohammed.bakkali.10@ucl.ac.uk. 